\title{
EL CUENTO DE LOS HERMANOS GRIMM «EL REY RANA O ENRIQUE -EL- FÉRREO»: RECEPCIÓN DEL LECTORADO INFANTIL Y DE LOS ENSEÑANTES EN ESPAÑA. PROPUESTAS PARA LA ENSEÑANZA DESDE UNA PERSPECTIVA DE GÉNERO
}

Elvira LUENGO GASCÓN

Universidad de Zaragoza

eluengo1@unizar.es

\section{Resumen}

En este artículo se muestran los resultados de la investigación realizada en diferentes centros educativos españoles en torno a la recepción del cuento, "El Rey rana o Enrique -el- férreo" de los Hermanos Grimm. El imaginario colectivo influye en las niñas, en los niños, en sus docentes y también en los estudiantes de la Universidad. Se analizan en los tres niveles las respuestas lectoras, los estereotipos desde una perspectiva de género y las propuestas de los docentes para una educación literaria desde los cuentos de hadas. ¿La respuesta de la princesa responde a un acto de sumisión o a un acto de rebelión? Finalmente, la experiencia personal de la lectura es la que construye el aprendizaje literario.

Palabras clave: "El Rey rana o Enrique-el-férreo", Hermanos Grimm, conversación literaria, propuestas didácticas con perspectiva de género. 


\title{
LE CONTE DES FRÈRES GRIMM « LE ROI GRENOUILLE OU HENRI-DE-FER » : RECEPTION DU LECTORAT ENFANTIN ET DES ENSEIGNANTS EN ESPAGNE. PROPOSITIONS POUR L'ENSEIGNEMENT À PARTIR D'UNE PERSPECTIVE DE GENRE
}

\section{Résumé :}

Cet article montre les résultats de la recherche effectuée dans différents centres éducatifs espagnols autour de la réception du conte « Le Roi-grenouille ou Henri-de-fer » des Frères Grimm. L 'imaginaire collectif a une influence sur les filles, les garçons, leurs enseignants et aussi sur les étudiants universitaires. Aux trois niveaux, sont analysées les réponses des lecteurs, les stéréotypes d'une perspective de genre et les propositions des enseignants pour une éducation littéraire à partir de contes de fées. La réponse de la princesse répond-elle à un acte de soumission ou à un acte de rébellion? Finalement, c'est l'expérience personnelle de la lecture qui construit l'apprentissage littéraire.

Mots clés: «Le Roi grenouille ou Henri-de-fer», Frères Grimm, conversation littéraire, propositions didactiques avec une perspective de genre.

\section{THE STORY OF THE BROTHERS GRIMM «THE FROG KING OR IRON HENRY»: RECEPTION BY CHILD READERSHIP AND TEACHERS IN SPAIN. TEACHING SUGGESTIONS FROM A GENDER-BASED PERSPECTIVE}

\begin{abstract}
In this article, results are shown from the research project carried out in different Spanish schools with respect to reception of the children's tale, "The Frog Prince”. The collective imagination doesn't make an impact just on girls, boys, and their teachers, but also university students. The analysis encompasses reader reaction on these three levels, along with stereotypes from a gender perspective and proposals
\end{abstract}


by teachers for a literary education through fairy tales. Does the princess's reaction constitute an act of submission or one of rebellion? Finally, the personal experience of reading is what builds literary learning

Key Words: «The Frog King or Iron Henry», The Brothers Grimm, literary conversation, didactic proposals with a gender-based perspective.

\section{Introducción. El cuento de los Hermanos Grimm «El Rey rana o Enrique-el-férreo»}

«El Rey rana o Enrique el Férreo» es el cuento más emblemático de los Hermanos Grimm por el tratamiento que siempre le dieron sus autores en todas las ediciones de Kinder-und Hausmärchen desde su primera edición en 1812. Los autores que se han adentrado en descifrar las múltiples reescrituras, traducciones y adaptaciones del texto, o bien los artistas que se han sentido atraídos por él y han imaginado infinidad de lecturas configurando imágenes inquietantes, van desgranando todos los enigmas que entraña el cuento. Por otro lado, la crítica especializada va descubriendo las razones profundas que sostienen a "El Rey rana" en las variadas reconfiguraciones transculturales. Puede afirmarse que estamos ante un cuento que pertenece a la literatura crossover, como ha demostrado Sandra Beckett en su libro Crossover Picturebooks: A Genre for All Ages (2013).

Todorov señala en La littérature en péril (2007) que el lector, en las obras literarias, busca darle sentido a su existencia, por ello es el lector quien tiene la razón cuando infiere el mensaje e interpreta el texto. La experiencia personal de la lectura constituye el aprendizaje literario. En esta línea de investigación, la de la estética de la recepción, se presenta un recorrido en el eje educativo (desde la infancia y desde los estudiantes universitarios hasta el profesorado inmerso en la docencia) de las diversas interpretaciones en las que se observa la identificación de las niñas y los niños con los personajes, con el príncipe, con la princesa, o con la rana, comprendiendo la respuesta de la princesa de maneras diferentes; como afirma María Tatar (2012), unas veces como un acto de subordinación al padre y otras como un acto de rebelión. La princesa se sitúa entre la subordinación y la rebelión, el Príncipe en la tentativa de recuperar su identidad desde la metamorfosis y Enrique, Heinrich -elférreo, representa el amor y la fidelidad. ¿Cuál es la recepción del cuento “El Rey rana o Enrique, 
El cuento de los Hermanos Grimm «El Rey rana o Enrique-el-férreo»: recepción del lectorado...

Heinrich -el -férreo" en el ámbito español? La compasión y la subordinación conducen al auténtico amor, como ocurre en la "Bella y la Bestia", en cambio "El rey sapo" respalda un acto de rebeldía y la expresión de sentimientos genuinos como señala María Tatar (2012).

Se destacan algunas cuestiones fundamentales de gran interés en relación al estudio histórico del cuento relacionadas con el grado de conocimiento del relato por parte de los participantes y las características de las versiones conocidas. En primer lugar, es preciso tener en cuenta lo que ofrecen las diferentes y numerosas versiones encontradas y clasificadas del cuento «El Rey rana o Enrique el férreo», también llamado «El Rey sapo» en España y América, (Espinosa, 1945; Rodríguez Almodóvar, 1995; Boggs, 1930) y en el contexto europeo (Tatar, 2012; Bettelheim, 2006). Por otro lado, las reediciones del cuento destinadas a los jóvenes de hoy y sus diversas interpretaciones que se encuentran en el mercado editorial son muchas y variadas ${ }^{1}$.

Se establece un interesante dialogismo intertextual que relaciona este cuento con El asno de oro de Apuleyo, con el mito de « Eros y Psique», con el mito de Melusina y con La Bella y la Bestia de Mme. Leprince de Beaumont. Es destacable igualmente la proximidad y la fusión de estos motivos, cuentos, mitos, leyendas y narraciones entre versiones y traducciones francesas y españolas como ocurre con $E l$ Conde Partinuplés de Blois. Se abren paso numerosas reescrituras y numerosas lecturas².

La investigación se centra en "El Rey rana", cuento que pertenece al ciclo del "animal-novio", al igual que la Bella y la Bestia que integra el mito de Eros y Psique. Los protagonistas son el anfibio que representa la sexualidad y sufre una metamorfosis y la joven rebelde, valiente y desobediente que rechaza la autoridad del rey, su padre. El cuento podría decirse que constituye un relato de aprendizaje o de iniciación, una historia ejemplar, un cuento moral o una historia de subversión, quizá un cuento de emancipación. Según Bettelheim (2012), la pelota que cae al agua representa la pérdida de la inocencia.

1 Algunos libros de "El Príncipe rana" editados y traducidos en español: Aretzaga, M. Teresa. (2005). Rana por un día. Barcelona: Ed. Cast.: Edebé. Gaarder, Jostein. (2005). El castillo de las ranas. Madrid: Siruela. Selfors, Suzanne. (2015). Besos y Hechizos. Barcelona: Alfaguara.Umansky, Kaye. (1993). Toda la verdad sobre el príncipe rana. Madrid: Ed. Rialp

2 Puede verse en Elvira Luengo Gascón. (2014). La reinvención de la identidad femenina bajo el monomito universal en Contenidos especializados en la enseñanza superior. Coord. Graciela Padilla Castillo. Editorial ACCI. Colección Nuevo Impulso Educativo. España. pp. 305-318. Y también: Luengo Gascón, E. (2007). Diacronía y Semiótica del cuento folclórico. El poder de El conde Partinuplés: Un juego entre la palabra y el sentido. Lectura y universidad. (Seminario interfacultativo de lectura) coord. por Eloy Martos Núñez, Ángel Suárez Muñoz, Agustín Vivas Moreno, pp. 311-316. 
Se trata verdaderamente de una historia unida a la psicología y a la sexualidad, pero, además, aparecen temas relacionados con la igualdad y la ruptura de los estereotipos de género.

La versión castellana de El Conde Partinuplés responde a la novela francesa Partonopeus de Blois compuesta hacia 1180 y constituye una de las primeras leyendas melusinianas traducidas a todas las lenguas del Occidente medieval (Lecouteux, 1982). La novela francesa se ha atribuido a Denis Pyramus que recrea el cuento de "La Bella y la Bestia", como "El Rey rana". En El Conde Partinuplés, con la protagonista Melior se invierte el papel masculino del cuento tradicional. Como señala Harf Lancner “Mélusine c'est Morgue apprivoisée. C’est l'euphémisation des forces obscures de la féminité: en elle s'épanouit la magie bénéfique de la femme, féconde, maternelle, éminemment rassurante par sa soumission aux lois humaines (1984, p. 433-434). Delpech afirma que estos relatos han conservado restos folclóricos muy específicos y que "L’héroïsme féminin qu'ils évoquent est essentiellement matronal" (1994, p. 28).

En la novela de Portonopeu de Blois, Melior acaba practicando un heroísmo de integración y de sociabilidad y se confirman las palabras de F. Delpech. "El heroísmo masculino del Conde finalmente difiere del tratamiento narrativo que se le concede a Melior. En Melior reside no sólo el ingenio y la astucia sino toda la magia, engaños y encantamientos propios de su condición genérica" (Luengo, 2014, p. 313).

En "El Príncipe rana", la princesa demuestra tener carácter y se rebela contra su padre y contra la rana que le impone que se acueste con ella, pero la reacción de la princesa es lanzarla contra la pared. Aun así, al final, el cuento acaba con la celebración de la boda tras la metamorfosis de la rana en príncipe. De manera que:

\footnotetext{
El antagonismo intersexual, lúdico, remite a una pantomima de guerra de sexos. Es pues, como señala Delpech, una ficción ritual que expresa simbólicamente, reequilibrándola, la diferencia entre la realidad social vivida -que impone una continua colaboración de sexos-, y la estructura formal-ideológica del sistema, que postula una dominación masculina (Luengo, 2014, p. 313).
}

El cuento de "La Bella y la Bestia" (425 C, según la clasificación de Aarne-Thompson) es uno de los más conocidos de este ciclo. La versión más famosa y más popular de esta narración es la de Madame Gabrielle-Suzanne de Villeneuve, publicada en 1740. En la versión de Villeneuve se pone de manifiesto el tema de los matrimonios forzados o forzosos como ocurre con el cuento de "El Rey 
El cuento de los Hermanos Grimm «EI Rey rana o Enrique-el-férreo»: recepción del lectorado...

rana" en el que acaba consolidándose ese matrimonio deseado, desde el principio del cuento, por el “animal-novio" y por el padre.

“E1 Príncipe rana”, como señala Aurelio Espinosa, en su obra Cuentos populares españoles, publicada en 3 volúmenes $(1945,1947,1947)$, forma parte de "El Príncipe encantado" (que agrupa, además, otros cuentos). Responde al esquema de "El animal-novio" según analiza Bruno Bettelheim (2012). Estos cuentos de hadas abordan la lucha por la madurez que los niños deben afrontar y simbolizan el cambio radical que debe producirse para alcanzar el amor y la felicidad. Las represiones sexuales en la infancia conducen al rechazo del otro sexo en la madurez (Bettelheim, 2012). En nuestro cuento se simboliza por el asco de la princesa hacia la rana. El ciclo de "La princesa encantada" y el cuento de "La princesa mona" comparten algunos elementos con el cuento que analizamos.

A partir del siglo XVIII y sobre todo el XIX, el cuento de "La Bella y la Bestia”, como analiza María de la Pau Janer (2015, p. 121), en sus múltiples variaciones, "se encuentra en todas las recopilaciones de cuentos populares de Europa y en algunos países de América Latina. También en Asia Central y en África. Lo hallamos en la de A. M. Espinosa $(1987,1988)$ y en toda el área lingüística del castellano (Camarena, Chevalier, 1995, p. 251-254)".

\section{Investigación. Recepción del lectorado infantil y de los enseñantes en España.}

En estas páginas presentamos la investigación desarrollada en torno a la recepción del cuento en tres niveles de lectores que provienen de la lectura de niñas y niños de educación primaria, de estudiantes de la universidad y de la práctica docente de maestras y maestros de Aragón. Dentro de este pluriperspectivismo de miradas y lecturas posibles que admite el cuento, este estudio quiere aportar otra distinta centrada en las respuestas lectoras de niñas y niños de educación infantil y educación primaria y en las respuestas de jóvenes estudiantes universitarios. Especialmente, importa conocer, asimismo, el punto de vista de los docentes ante la tarea personal de la comprensión e interpretación de "El Rey rana", queremos ahondar en cómo se desarrollan las prácticas educativas respecto a la educación literaria, en concreto cuáles son las estrategias didácticas que se activan en los centros educativos para este género literario, el cuento. La focalización de esta investigación expone la doble vertiente de enseñanza y aprendizaje, se concentra en la recepción de estudiantes y de docentes y en 
las propuestas de los enseñantes. Se describe el concepto de la investigación, los participantes en su contexto, la metodología y los instrumentos utilizados en las etapas del proceso de intervención, el análisis de los resultados y las conclusiones.

\subsection{Participantes y metodología}

Para averiguar cuál ha sido el destino en la literatura infantil y juvenil de «El Rey rana o Enriqueel-férreo» la investigación se focaliza en los siguientes niveles:

En primer lugar se muestran los resultados de la recepción del cuento por parte de los lectores infantiles. Se analizan las respuestas lectoras en niñas y niños de educación primaria desde una perspectiva de género. Los niños de las escuelas que han leído, escuchado y comprendido el cuento del Rey rana, han participado en las actividades didácticas y han respondido a las diversas cuestiones que conlleva el enfoque de la conversación literaria que propone Aidam Chambers. Se ha utilizado, además, como instrumento de investigación la encuesta, para completar el grado de comprensión del cuento.

En segundo lugar se ha investigado acerca del grado de conocimiento del cuento de los estudiantes universitarios en la Facultad de Educación de Zaragoza; les pedimos que contaran lo que recordaban de "El Rey rana" desde la versión que conocían. Dichos recuerdos influyen en la recepción actual del cuento. Los estudiantes, como futuros enseñantes y maestros en formación, durante los cursos 201516 y 2016-17 han trabajado este cuento con la profesora en clase y han respondido a cuestionarios que aportan datos en torno a la cantidad, estructura de los recuerdos conservados y a las inferencias individuales positivas y negativas respecto a sus personajes, encontrando diferencias entre las respuestas de los chicos y de las chicas frente a las acciones del rey, de la princesa y de la rana.

En tercer lugar se pretendía analizar la recepción del cuento entre las maestras y maestros en educación infantil y en educación primaria ¿Cómo se comprende y cómo se enseña en el ámbito escolar? Los docentes de educación infantil (5 años) y de educación primaria (6-12 años), maestros y maestras de casi 50 colegios de Aragón tanto públicos como concertados, rurales y urbanos han colaborado en la investigación accediendo a permitirnos entrar en sus aulas para investigar acerca de la recepción y de las respuestas lectoras de este cuento por parte de las niñas y los niños.

Finalmente, se presentan los resultados de las encuestas abiertas y entrevistas realizadas a los 
El cuento de los Hermanos Grimm «El Rey rana o Enrique-el-férreo»: recepción del lectorado...

docentes. Para mostrar su enfoque didáctico respecto a la enseñanza y aprendizaje de los cuentos a la vez que hemos conocido sus propuestas de intervención o actividades que sugieren para trabajar los cuentos de hadas y la educación literaria con estudiantes de infantil y primaria en las aulas.

La recepción del cuento se convierte en un diálogo entre los niños y los enseñantes. El propósito de este estudio es investigar ese dialogismo que se establece en la recepción de “El Rey rana”, entre los niños en la escuela, sus maestras y maestros y asimismo entre los maestros en formación, estudiantes en la Universidad y los docentes de estos últimos. Esta red de lecturas configura una rica polifonía que revela un conjunto de diferentes voces ante un mismo texto.

Antonio Mendoza, así lo describe cuando define los componentes de la competencia literaria en su artículo "Función de la literatura infantil y juvenil en la formación de la competencia literaria"3:

Para M. Stubss (1987, p. 204), "la competencia literaria supone la capacidad de comprender distintos tipos de relación semántica, entre lo que se dice y lo que se implica": "por ello se considera fundamental para el desarrollo de la competencia literaria atender a la actividad interpretativa propia del receptor" (Thomas, 1978, p.44), que se construye en el marco de una semiótica integral y en relación con la pragmática literaria. Esta concepción comparte los supuestos expuestos por Umberto Eco $(1979$, p. 16) respecto al hecho de que «el lector como principio activo de la interpretación, forma parte del marco generativo del propio texto».

Como objetivos destacamos dos fundamentalmente: observar la influencia de los cuentos en la formación de los estereotipos sexistas y conocer la opinión de los enseñantes respecto a la formación de estos estereotipos de género en los lectores y lectoras según la educación literaria que han recibido. El segundo de estos objetivos nos descubre las preferencias de los docentes y las estrategias didácticas respecto a la enseñanza de la literatura. En el análisis de resultados se tendrá en cuenta, entre otros aspectos, el grado de conocimiento del cuento de «El Rey rana » por parte de los participantes. Partimos de la hipótesis de que la literatura transmite estereotipos de género muy marcados que refuerzan los adquiridos por los niños y niñas desde los medios de comunicación, la escuela y el entorno social en el que se desarrollan. Se muestran los resultados a continuación a través de las respuestas a los cuestionarios, mediante las conversaciones literarias, entrevistas y demás intervenciones en las aulas.

\section{La recepción del cuento en la educación primaria}

¿Cuáles son los cuentos que los niños y las niñas prefieren?

$3 \mathrm{http} / /$ www.cervantesvirtual.com/obra/funcin-de-la-literatura-infantil-y-juvenil-en-la-formacin-de-la-competencialiteraria-0/ 
En una muestra de 40 niños y niñas entre 10 y 12 años (quinto y sexto curso de educación primaria), el $8 \%$ conocían el cuento de "El Rey rana" frente al $92 \%$ que respondieron que lo desconocían.

Al preguntar por los cuentos populares más familiares para ellos responden con los siguientes títulos como los más leídos: "Blancanieves", "Pulgarcito", "Cenicienta" y "Caperucita roja" tanto los chicos como las chicas.

A la pregunta de ¿qué cuentos eran sus preferidos? las respuestas obtenidas más significativas son las siguientes: entre 8 respuestas y 4 respuestas, en orden de más preferidos a menos preferidos: “Caperucita roja" (chicas), "Blancanieves" (chicas), "Los tres cerditos" (chicas y chicos), "Cenicienta" (chicas), "La Bella durmiente" (chicas). Con 4 respuestas, la mitad de respuestas que para los cuentos anteriores, responden con estos títulos: "Pinocho" (chicas y chicos), "Frozen" (chicas y chicos) y "Toy Story" (chicas y chicos). Con 2 respuestas solamente aparecen los siguientes cuentos: "La Sirenita" (chica y chico), "Rapunzel” (chicas), "La Bella y la Bestia” (chicas), "Hansel y Gretel” (chica y chico) y "Brave" (chicas). Con 1 respuesta (sólo chicas): "Tiana y el sapo", "Patito feo", "Peter Pan", "Piel de asno", “Alí Babá y los 40 ladrones”. Con 1 respuesta (sólo chicos): "El capitán barbanegra”, "Robin Hood", "El gato con botas".

En estas respuestas se manifiesta claramente la preferencia de las chicas por historias en las que las protagonistas sean chicas y a la inversa ocurre lo mismo, los chicos prefieren leer libros con protagonistas masculinos con los que puedan identificarse. Se deduce de estas respuestas que los estereotipos de género se mantienen vivos en nuestra sociedad.

Hélène Montardre (1994), escribe que no se pueden separar los personajes reales de los personajes de papel porque los primeros son los creadores de los segundos y estos personajes de papel influyen sobre el desarrollo del niño-lector. Volvemos al imaginario colectivo y personal y a sus representaciones en la literatura infantil y juvenil. Raoul Dubois (1977) defiende que "Comme toute action éducative, la littérature pour la jeunesse exerce deux fonctions: l'une de reproduction de la société où elle apparait, l'autre de contestation de cette société" (cit. en Montardre, 1994, p.29). Los autores de Literatura juvenil ejercen un papel muy importante en esta representación o contestación a la sociedad, incluso aunque ellos no lo sepan e incluso aunque ellos no lo deseen. Ellos continúan transmitiendo la imagen de la sociedad tal como es, simplemente colocando en primer plano, como ocurre en la vida, a los héroes-chicos (Montardre, 1995). 
El cuento de los Hermanos Grimm «El Rey rana o Enrique-el-férreo»: recepción del lectorado...

Respecto al cuento de "El Rey rana”, después de haberlo leído en clase, un 84\% manifiesta que sí les gusta mientras que el resto, un $6 \%$, afirma lo contrario.

\section{La recepción del cuento de los estudiantes de la Universidad}

\subsection{Conocimiento del cuento}

En la encuesta sobre hábitos lectores realizada a los estudiantes de segundo curso de Magisterio, especialidad en educación primaria, en el curso 2015-2016 se pretendía averiguar, entre otros aspectos, el grado de conocimiento que los estudiantes tenían de este cuento. El número total de participantes fue de 54 estudiantes con edades entre 19 y 29 años; este grupo está formado por 45 mujeres y 9 hombres. Se les pregunta por los recuerdos que tienen del cuento "El Rey rana". Las estudiantes destacan por recordar muchos más aspectos del cuento que los chicos y lo que más recuerdan es la metamorfosis del príncipe y la obligación de la princesa de abrazar a la rana. Los chicos responden a la mitad de las preguntas solamente, hay que recordar que la proporción de chicos en el grupo es mucho menor que la de chicas. Algunos de los resultados obtenidos pueden verse en el Gráfico 1.

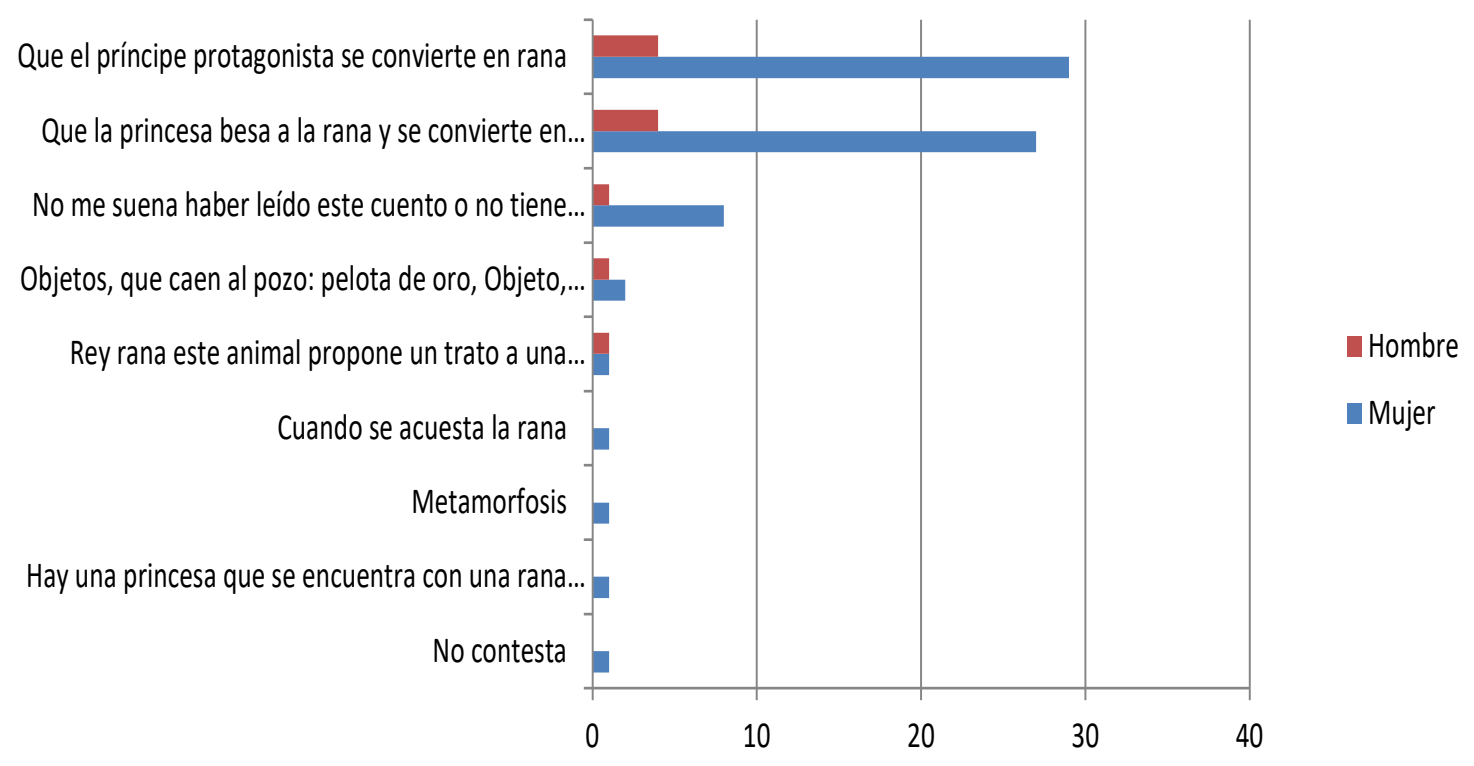

Gráfico 1. Encuesta a estudiantes universitarios. ¿Qué recuerdos tienes del cuento "El Rey rana"? Fuente: propia

En el curso 2016-2017, se realizó de nuevo una encuesta a los estudiantes de segundo curso de Magisterio, en este curso fue en la especialidad de educación infantil. El número total de participantes en este caso fueron 45. Este grupo estaba formado por 43 mujeres y 2 hombres. A la pregunta de si 
conocen el cuento de "El rey rana", esta vez responden afirmativamente 13 personas y negativamente 32, es decir, un $29 \%$ conocía el cuento frente al $71 \%$ que afirmaba no conocerlo como se aprecia en el Gráfico 2.

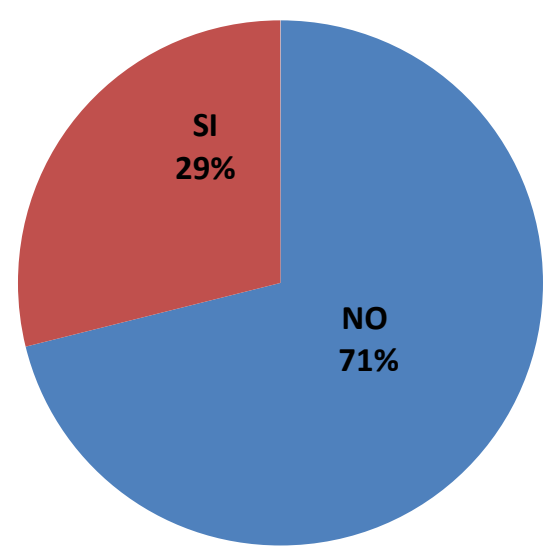

Gráfico 2. Encuesta a estudiantes universitarios (2016-2017). ¿Conoces el cuento de "EI Rey rana"? Fuente: propia

\subsection{Hábitos lectores}

En la misma encuesta, a los estudiantes de segundo curso de Magisterio (se trata del mismo grupo que el de la pregunta anterior), se les preguntaba por sus hábitos lectores. A la pregunta sobre estos hábitos ¿te gusta leer? los estudiantes responden con los siguientes resultados: 2 estudiantes responden Nada, 15 estudiantes afirman que les gusta leer Poco, 21 manifiestan que les gusta leer Bastante y finalmente, en la escala más alta, 7 estudiantes confiesan que les gusta leer Mucho (Gráfico 3). Es preocupante que un $37 \%$ de universitarios, futuros maestros y maestras, responda que les gusta leer poco o nada. 
El cuento de los Hermanos Grimm «El Rey rana o Enrique-el-férreo»: recepción del lectorado...

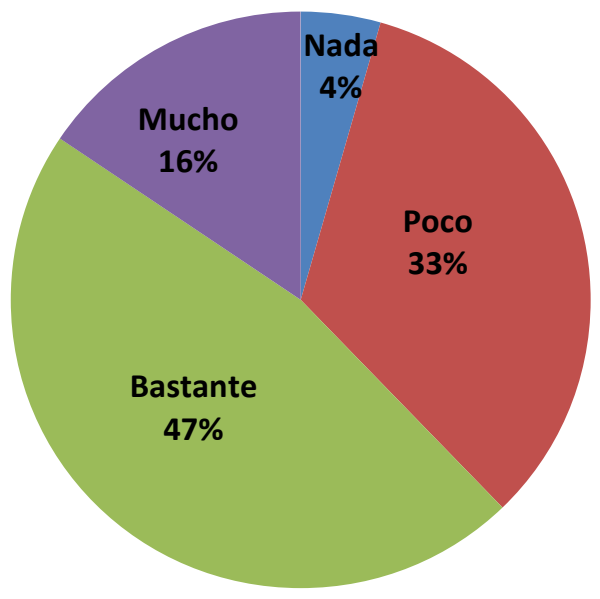

Gráfico 3. Encuesta a estudiantes universitarios. Hábitos de lectura: ¿Te gusta leer? Fuente: propia.

\section{Respuestas de las maestras y maestros de centros educativos de infantil ${ }^{4}$ y primaria $^{5}$ en} Aragón

\subsection{Número y procedencia de maestras y maestros entrevistados}

En este tercer grupo de la investigación, nos interesaba delimitar bien la dedicación docente de las maestras y maestros. ¿En qué curso imparten su docencia? La muestra la constituyen 46 docentes; solo un $2 \%$ pertenecen a Educación infantil (último curso); otro $2 \%$ son docentes de un $\mathrm{CRA}^{6}$, es decir, de un Colegio Rural Agrupado en el que conviven juntos en una misma clase estudiantes de $3^{\circ}, 4^{\circ}, 5^{\circ} \mathrm{y}$ $6^{\circ}$ de Educación primaria; el $96 \%$ por ciento restante de los docentes participantes pertenece a los seis cursos de la etapa de Educación Primaria. Destaca la participación de profesorado de los cursos de $1^{\mathrm{o}}$ y de $4^{\circ}$ con el mismo porcentaje, un $44 \%$ entre los dos niveles.

4 Las maestras de educación infantil que han participado corresponden al último curso de educación infantil, con niñas y niños de 5 a 6 años.

5 Han participado maestras y maestros de educación primaria de todos los cursos de esta etapa (de primero hasta sexto) con niñas y niños desde los 6 años hasta los 12 años.

6CRA: Colegio Rural Agrupado 


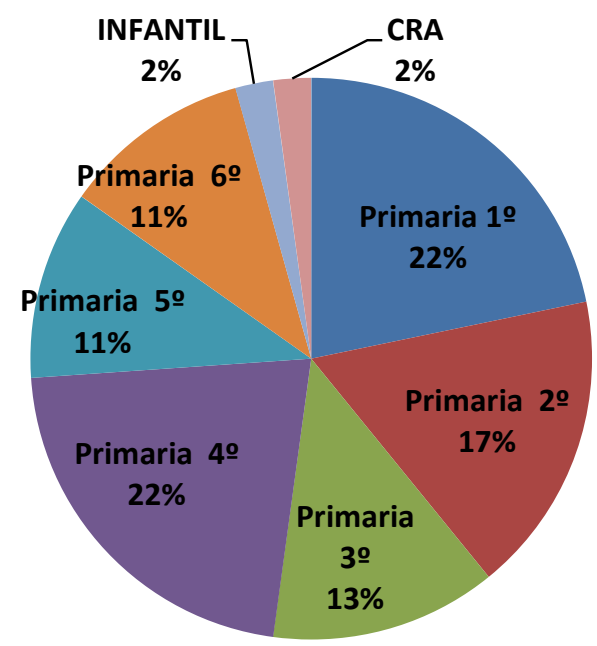

Gráfico 4. Encuesta a docentes. Porcentajes de docentes entrevistados por curso. Fuente: propia

\begin{tabular}{|c|c|}
\hline CURSOS & EDAD de los niños y niñas \\
\hline $1^{\circ}$ Primaria & 6 años \\
\hline $2^{\circ}$ Primaria & 7 años \\
\hline $3^{\circ}$ Primaria & 8 años \\
\hline $4^{\circ}$ Primaria & 9 años \\
\hline $5^{\circ}$ Primaria & 10 años \\
\hline $6^{0}$ Primaria & 11 años \\
\hline Infantil & 5 años \\
\hline $\operatorname{CRA}\left(3^{\circ}, 4^{0}, 5^{\circ}\right.$ y $\left.6^{\circ}\right)$ & $8,9,10$ y 11 años \\
\hline
\end{tabular}

Tabla 1. Equivalencia entre edades y curso en la Educación primaria en el sistema educativo español.

\subsection{Grado de conocimiento de los docentes del cuento}

En el siguiente gráfico se muestra el grado de conocimiento de los docentes respecto al cuento: un 53\% lo conocen. Estas cifras contrastan con el $29 \%$ de los estudiantes universitarios que manifiestan conocerlo (en gráfico 2). La muestra estudiada es de 46 docentes participantes y 45 estudiantes universitarios. Un primer factor que destaca es la edad de ambos grupos, los más jóvenes tienen un grado de conocimiento mucho menor de este cuento. Un $2 \%$ de los encuestados conoce este cuento con el nombre del "Rey sapo" 
El cuento de los Hermanos Grimm «El Rey rana o Enrique-el-férreo»: recepción del lectorado...

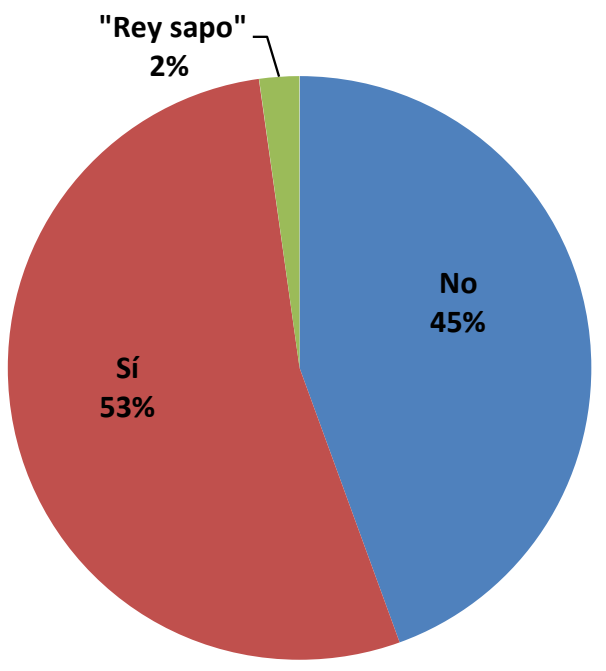

Gráfico 5. Encuesta a docentes. ¿Conoces el cuento de “El Rey rana”? Fuente: propia

Sin embargo, con las respuestas de las siguientes preguntas se puede inferir cuándo se ha leído el cuento, no en la infancia precisamente, lo que nos muestra que no se ha trabajado a nivel institucional desde la escuela. Solo un 15\%, es decir, 7 personas, confiesan conocerlo desde la infancia pero no sabemos si se lo han contado en la familia, en el colegio o lo conocen por otros medios. Casi la mitad de los docentes lo han leído de adultos, esta respuesta tampoco garantiza que en esos casos se haya trabajado en el contexto universitario.
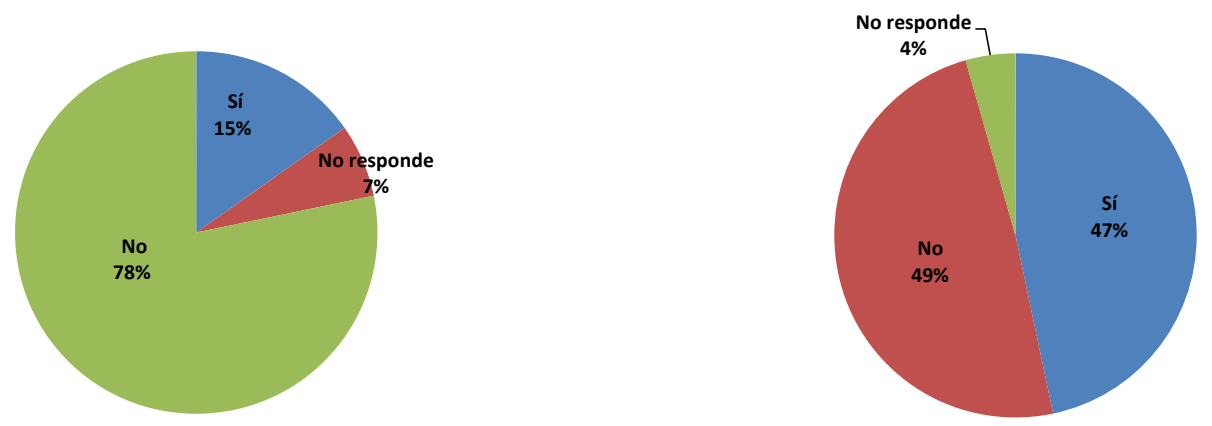

Gráfico 6. Encuesta a docentes. ¿Has escuchado el cuento Gráfico 7. Encuesta a docentes. ¿Lo has leído de cuando eras pequeño? Fuente: propia adulto/a? Fuente: propia 


\section{3 ¿Qué recuerdas de la versión leída de "El rey rana"?}

En cuanto a la pregunta ¿qué cambios recuerdas respecto a la versión leída?, se confirma lo que la crítica especializada viene afirmando. Brigitte Louichon (2009) expone:

J'ai mené une petite enquête auprès d'adultes, relative aux souvenirs laissés par la lecture du Vilain petit canard d'Andersen. Il est tout à fait frappant de voir que, quel que soit l'âge de la personne, quelle que soit l'ancienneté du souvenir et quel que soit le contexte de la lecture [...] les lecteurs se souviennent à peu près de la même chose : un personnage (le petit canard), une quête (il est rejeté par les autres et s'en va), une fin (il retrouve sa famille) et une moralité (conte sur la différence, l'identité...). Tout le reste est oublié. Reste une structure qui combine schéma narratif, schéma actanciel et axiologie. (Louichon, cit. en Conan-Pintado y Tauveron 2013, pp. 367-368).

El cuento de los Grimm es mal conocido y se constata la existencia de un gran desconocimiento en España (al menos en Aragón, teniendo en cuenta la dimensión de la muestra tomada). Sin embargo, la mayor parte de los motivos que las maestras y maestros recuerdan del cuento constituyen los elementos más representativos, significativos y conflictivos que configuran el arquetipo de "El Rey rana". El motivo del beso que preludia el romántico final en boda es lo que más se recuerda y quizá lo que más haya sido difundido y repetido por las numerosas versiones, aunque sabemos que en el texto fuente de los Hermanos Grimm esta escena no existe. Se observan afirmaciones con matices moralistas, tanto por lo que se afirma como por lo que se oculta, en cuanto a la presencia de testimonios como "el príncipe es bueno con la rana" o "la princesa no golpea a la rana". La ausencia de los elementos sensuales que contiene el cuento implica una censura que puede emanar, bien de las posibles versiones y lecturas realizadas, bien de la autocensura de los participantes o del contexto social entre otras razones. La presencia y la ausencia de unos recuerdos u otros determinan la asimilación y apropiación del cuento por parte de los docentes. Y efectivamente, como señala Louichon (2009) y Tauveron (2013), la memoria preserva y mantiene un esquema narrativo, un esquema actancial y axiológico. Así se demuestra también en esta investigación en todos los grupos de sujetos participantes y en todas las edades. Los recuerdos son guiados y se ven favorecidos por la rígida estructura del cuento folclórico como ya demostró Vladimir Propp y tantos otros folcloristas. La propia morfología universal del cuento de hadas colabora y facilita la ordenación mnemotécnica.

En esta selección de la memoria interviene la lectura en redes. Este tipo de lectura literaria en redes « distingue parmi les textes résistants, les textes réticents qui posent des problèmes de compréhension délibérés et les textes proliférants qui posent des problèmes d 'interprétation » (Tauveron, 1999, p. 25). Gervais piensa que « Le plaisir de la lecture est avant tout un plaisir partageable qui ne peut être partagé 
El cuento de los Hermanos Grimm «El Rey rana o Enrique-el-férreo»: recepción del lectorado...

que dans le cadre d'une intersubjectivité de nature culturelle, pour l'essentiel » (cit. en Tauveron, 1999, p. 25). Así, Catherine Tauveron describe diferentes redes que intervienen en la lectura literaria y las modalidades interpretativas como la red intertextual, intratextual, architextual, hipertextual, etc. A través de la investigación se descubre esta lectura en red que se bifurca en la mutabilidad de la recepción literaria puesto que como sabemos todo texto es un palimpsesto.

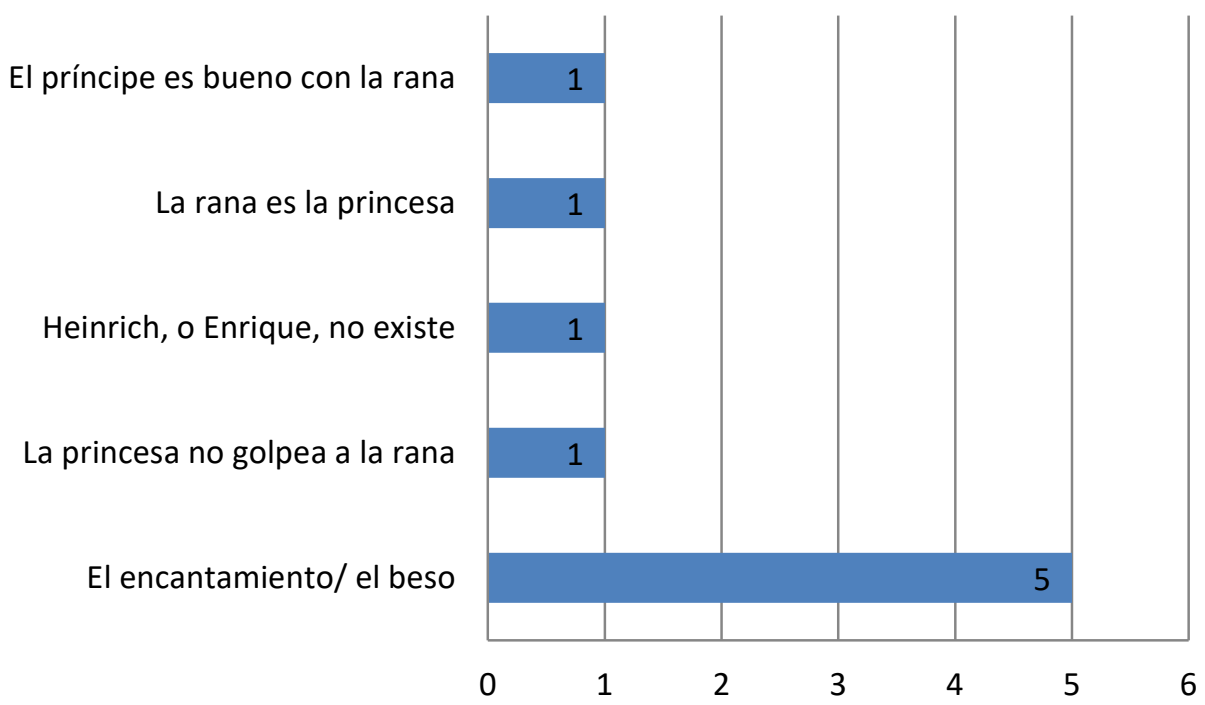

Gráfico 8. Encuesta a docentes. ¿Qué cambios recuerdas respecto a la versión leída? Fuente: propia.

\section{4 ¿Has trabajado este cuento con los niños como profesor?}

En el gráfico 9, que corresponde a la pregunta ¿Has trabajado este cuento con los niños como profesor?, se representa la proporción de docentes que han dado a conocer el cuento de los Hermanos Grimm en su ejercicio docente. Curiosamente, casi coincide exactamente el porcentaje de los docentes que no lo han trabajado en sus clases (76\%), con el porcentaje de los que no lo conocían en su infancia (78\%). Dicho en el sentido contrario y afirmativamente se constata que un 15\% lo leyó o se lo contaron en su infancia y un $17 \%$ de los docentes en los colegios, porcentaje muy similar, lo ha trabajado con sus estudiantes en la escuela. Podría decirse que los cuentos que se conocen desde la infancia perduran, se recuerdan y en este caso las maestras han optado por hacer que sus estudiantes participen igualmente de ese relato, del placer de disfrutar de ese cuento maravilloso. 


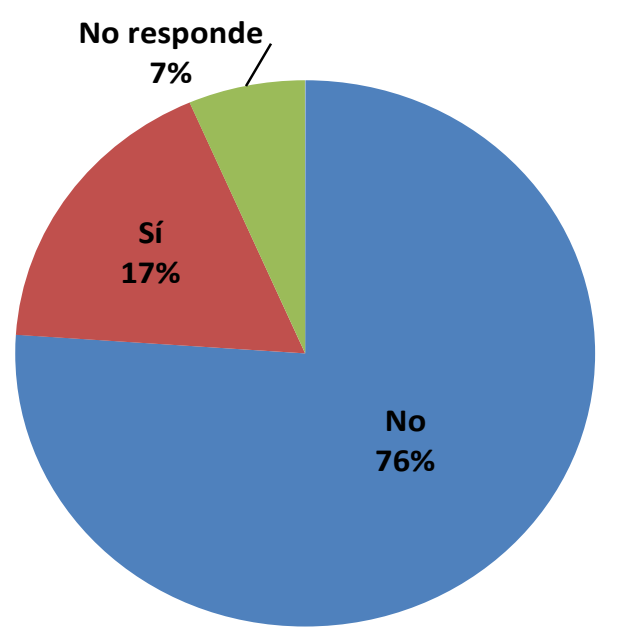

Gráfico 9. Encuesta a docentes. ¿Has trabajado este cuento con los niños como profesor? Fuente: propia.

\section{5 ¿Cómo y por qué has trabajado el cuento de "El Rey rana"?}

En la siguiente pregunta ¿Cómo y por qué has trabajado el cuento de "El Rey rana”?, que se resume en el gráfico 10, se pueden agrupar las respuestas en 3 categorías fundamentalmente como se observa. ¿Cómo se da a conocer el cuento? Los docentes confiesan que mediante la conversación literaria, la reflexión, la comprensión de la narración y el diálogo conjunto de la clase. Los valores que emanan de la conducta de la princesa, de lo que se espera de ella y de los estereotipos sociales asociados al género (masculino/femenino), de la imposición del padre y el final moralizante alcanzan una gran preponderancia en muchas de las respuestas.

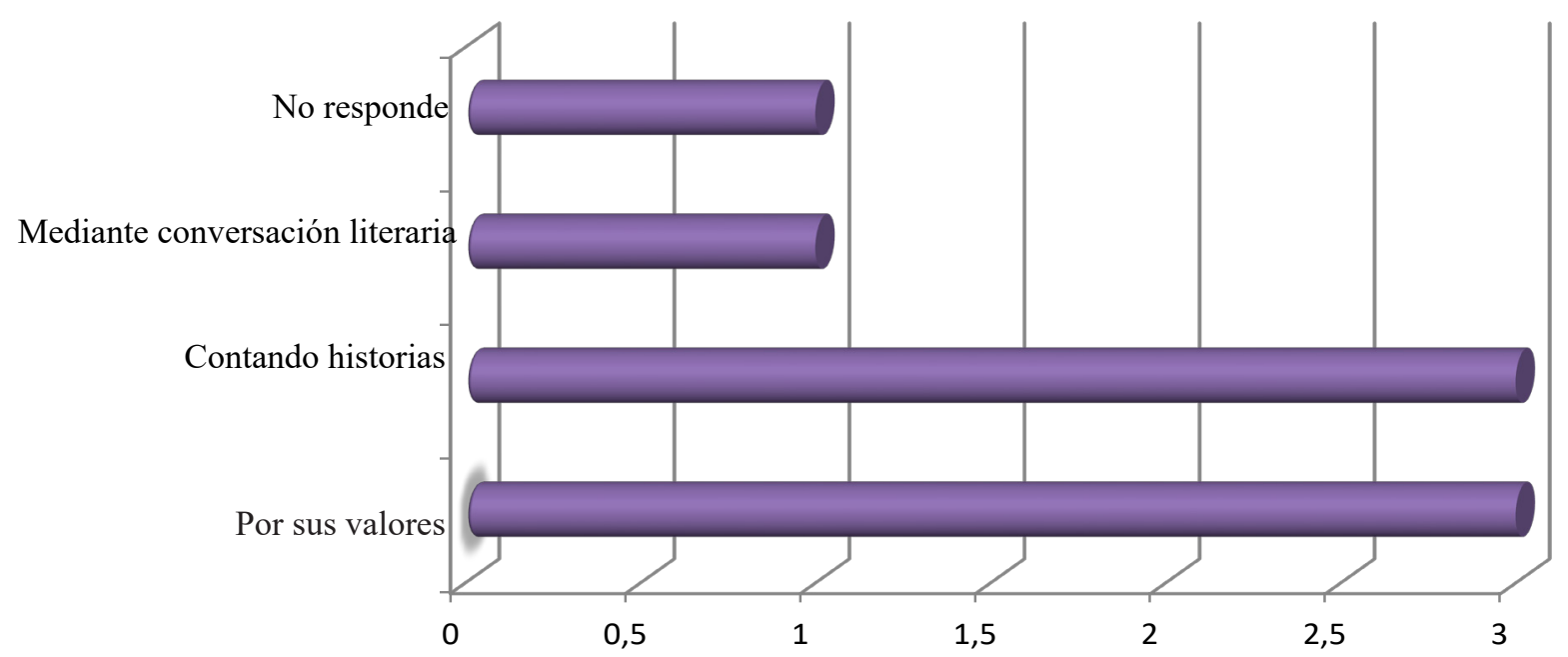

Gráfico 10. Encuesta a docentes. ¿Cómo y por qué has trabajado el cuento de “EI Rey rana”? Fuente: propia. 
El cuento de los Hermanos Grimm «EI Rey rana o Enrique-el-férreo»: recepción del lectorado...

\section{6 ¿Por qué piensas que este cuento de los Hermanos Grimm es mal, poco, o nada conocido?}

En el gráfico 11 se refleja un resumen de la opinión de los docentes acerca de esta pregunta, ellos exponen sus diferentes puntos de vista que se pueden agrupar en varias categorías. De las 46 respuestas obtenidas, 3 personas creen que se debe a las numerosas versiones existentes del cuento y, además, en esta línea 13 personas responden que el cuento se conoce mal, poco o nada debido a la difusión que ha tenido, y tiene, a través de las diferentes adaptaciones, editoriales, manuales escolares, versiones cinematográficas o adaptaciones para televisión u otros medios audiovisuales. Otros 11 docentes responden de una manera más indeterminada que se debe al grado de conocimiento o de ignorancia que se posee del cuento. Un grupo de 7 docentes cree que si el cuento se conoce mal, poco o nada se debe a la ideología que transmite. Desde otro punto de vista de la recepción del cuento, y centrándose en la recepción del lectorado infantil y juvenil, 5 docentes piensan que se debe a la adecuación o inadecuación de las adaptaciones a la edad de los niños y de los jóvenes. Se recogen también 2 respuestas que afirman que la causa reside en que el cuento se cuenta en la familia y no en la escuela. Y, finalmente, para 5 docentes el cuento es desconocido y no opinan. Con estas respuestas los docentes analizan y manifiestan los múltiples aspectos y matices que rodean a la experiencia literaria de los lectores, las lectoras y de la suya propia como responsables de la educación literaria en sus aulas. En síntesis lo vemos representado en el gráfico 11.

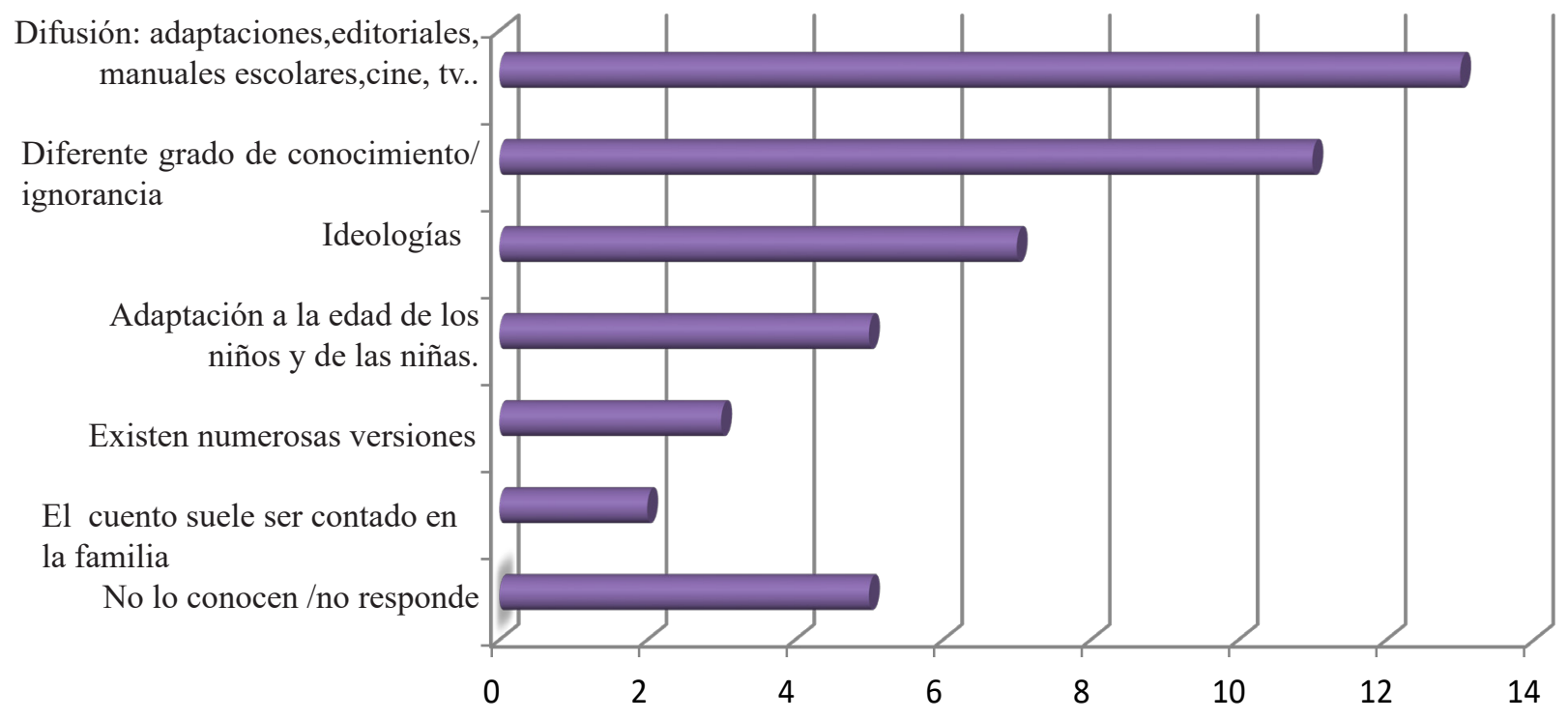

Gráfico 11. Encuesta a docentes. ¿Por qué piensas que este cuento de los Hermanos Grimm es mal, poco, o nada conocido? Fuente: propia 


\section{7 ¿Está de acuerdo con la selección de lecturas para cada curso de su centro?}

La mayoría manifiestan estar de acuerdo precisando la manera en la que se lleva a cabo la selección. 40 personas responden afirmativamente y matizan su respuesta aportando los criterios, las prioridades que tienen en cuenta, las discrepancias o lo que les gustaría modificar. Solamente 2 personas responden abiertamente no y otras 2 no contestan. La transcripción de las respuestas agrupadas son las que siguen a continuación:

- Sí, intentamos que se adapten a sus gustos.

- $\quad$ Sí, porque la elección la hace el profesorado y siempre con un motivo. Además esas lecturas se trabajan en clase

- $\quad$ Sí, porque están consensuadas por los equipos didácticos

- En mi caso selecciono lecturas de acuerdo a los tipos de texto que voy a trabajar y a los temas que interesan a mis alumnos.

- $\quad$ Se seleccionan por edades, pero es bueno que lean diferentes temáticas.

- $\quad$ Sí, porque trabajamos muchos cuentos que ayudan en el aprendizaje

- $\quad$ Sí, son adecuados en cuanto al vocabulario y también por los valores que transmiten.

- Sí, Los tutores establecemos la relación de los textos para la biblioteca de aula según nuestro criterio.

- Sí, es amplia, variada y siempre abierta para que cada alumno pueda aportar sus motivaciones e intereses.

- Sí, porque las lecturas son muy abiertas. Existen unos libros para trabajar en cada trimestre y, además, se trabajan otros sobre temas variados.

- En parte

- $\quad$ Sí, tenemos un Plan lector

- $\quad$ Sí, porque se seleccionan teniendo en cuenta la edad, los intereses y los gustos de los niños.

- La decidimos entre los compañeros.

- Tenemos una biblioteca donde cada niño puede elegir aquella lectura que más le interesa. En el curso se trabajan unos libros que seleccionamos y procuramos que sean de interés para los alumnos.

- Cada profesor escogemos las lecturas de nuestro curso.

- Si las adaptamos a las situaciones que se crean.

- En los libros de lectura que publican las editoriales para cada nivel de edad hay algunas con lecturas muy insulsas, también es verdad que hay alguno que merece la pena.

- Me gustaría muchas más y con mayor profundidad que la de hacer fichas resumen. Pero no hay tiempo para todo.

- La selección de mi centro sólo es un libro para todo el curso con el que se hace un proyecto de centro y es elegido de forma consensuada por el claustro. Los demás los elijo dependiendo del tipo de lectura.

- Sí, ya que soy una de las impulsoras del plan lector.

- En general están de acuerdo a los años de los niños con los que trabajamos pero desde luego podríamos trabajar otros.

- $\quad$ No, tenemos una selección prefijada para cada curso. Se eligen en función de los tutores que llevan el nivel.

- $\quad$ Sí, los niños se divierten leyendo

- $\quad$ No. Las lecturas y libros presentes en colegios en la mayoría de los casos están obsoletos o no hay suficientes adecuados a sus gustos e inquietudes.

- $\quad$ No. Creo que los niños son capaces de leer libros 2-3 años por encima de su edad 
El cuento de los Hermanos Grimm «El Rey rana o Enrique-el-férreo»: recepción del lectorado...

Los maestros y maestras confiesan tener en cuenta los gustos, las preferencias e intereses de sus estudiantes, procuran que la selección de las lecturas les divierta. Siguen el plan lector y trabajan con los libros de la biblioteca de aula.

A la hora de seleccionar las lecturas tienen en cuenta la edad de los lectores, los valores que transmiten y quieren ampliar las temáticas que se les ofrece a los niños; asimismo, valoran que haya consenso en el claustro de profesores aunque en muchos casos es la maestra o el maestro quien amplía ese corpus consensuado.

No siempre se está de acuerdo con lo que ofrecen las editoriales. Aparece, en 2 respuestas, una crítica abierta a la (des)actualización de las lecturas en los centros y a lo que se les ofrece a los niños, a veces por debajo de sus capacidades.

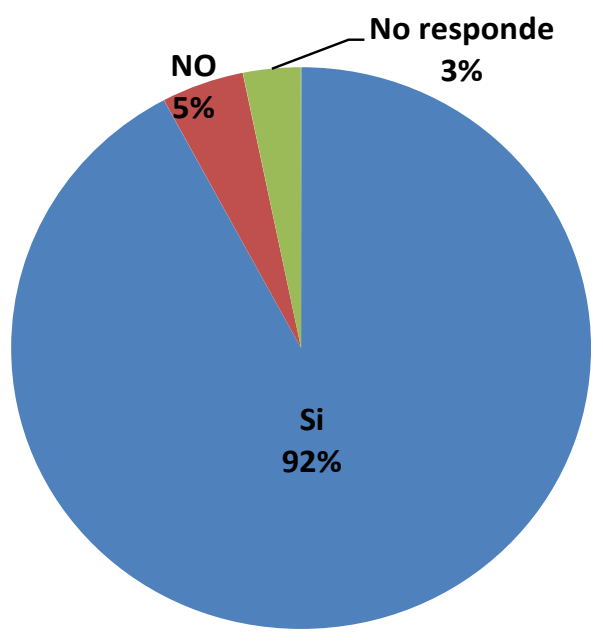

Gráfico 12. Encuesta a los docentes. ¿Estás de acuerdo con la selección de lecturas para todos los cursos de tu Centro?

\section{8 ¿Cree que los cuentos de hadas favorecen la enseñanza literaria y el desarrollo de los niños y niñas?}

De un total de 46 respuestas, 42 responden afirmativamente, uno no responde y 3 docentes manifiestan no estar totalmente a favor de los cuentos de hadas.

\subsubsection{Respuestas en contra de los cuentos de hadas:}

En las 3 únicas respuestas negativas aparece cierta ambigüedad, no están a favor de su lectura e incluso se afirma que su lectura no es favorable para el desarrollo de los niños: 
- $\quad$ Todo depende de la aproximación y de la intención perseguida

- Los cuentos no favorecen especialmente el desarrollo, pero yo no pienso que su influencia sea negativa. Se podría trabajar con cuentos de varios tipos para compararlos entre ellos.

- Los cuentos de hadas no son especialmente favorables al desarrollo de los niños y debemos animar la lectura de otro tipo de relatos.

\subsubsection{Respuestas a favor de los cuentos de hadas}

Además de la cuantificación de las respuestas, en el análisis cualitativo aparecen los matices que enriquecen la valoración de los docentes en torno a los aspectos que consideran más significativos acerca de la educación literaria.

Las 42 respuestas a favor de los cuentos de hadas, se pueden agrupar en tres categorías; los docentes afirman que favorecen: 1 el desarrollo de los valores, la imaginación, la creatividad y las emociones en los niños, 2 el desarrollo de los niños y la educación literaria y 3 el desarrollo del pensamiento crítico, la educación en igualdad y la no discriminación.

Se transcriben a continuación las respuestas categorizadas en tres grupos:

\section{1-Los cuentos de hadas favorecen el desarrollo de los valores, la imaginación, la creatividad}

\section{y las emociones en los niños.}

- Forman en valores (7 respuestas)

- Los cuentos desarrollan la utilización de la imaginación (10 respuestas); cada vez más la imaginación es más escasa entre nuestros niños.

- Los cuentos contienen historias para ayudar a estimular la creatividad (6 respuestas). Se puede desarrollar una educación literaria completa en los niños.

- Los cuentos enseñan a los niños cómo su creatividad y su imaginación pueden transportarlos a cualquier lugar.

- Los cuentos de hadas estimulan el desarrollo de las emociones y de los factores afectivos.

- Los cuentos de hadas ayudan a los niños a creer en sus sueños.

Podríamos resumir estas respuestas en seis sustantivos que recogen los beneficios que proporcionan los cuentos de hadas según la opinión de los docentes: valores, imaginación, creatividad, emociones, afectividad, sueños. Los niños aprenden a soñar con estos cuentos.

\section{2- Los cuentos de hadas favorecen el desarrollo de los niños y la educación literaria.}

- Favorecen la aproximación a la literatura

- Son fundamentales para crear el gusto por la lectura, estimulan la lectura

- Los cuentos ayudan a los niños a mejorar el vocabulario y la expresión oral

- Desarrollan la comprensión y la capacidad de analizar y de comprender los textos.

- En ciertos casos, desarrollan la expresión escrita.

- Ofrecen modelos lingüísticos ricos.

- El niño entra en contacto con el mundo mágico de los libros.

- Me parece importante trabajar y promover la educación literaria porque se aprenden muchas cosas, es divertido compartir aventuras y experiencias con sus compañeros. 
El cuento de los Hermanos Grimm «El Rey rana o Enrique-el-férreo»: recepción del lectorado...

- Es una forma de que los alumnos amplien su visión del mundo a través de estos relatos fantásticos

- Los cuentos de hadas forman parte de la literatura

- ...y porque son hermosos

La opinión de los docentes en este grupo de respuestas se fundamenta en:

la lectura por placer, en el juego con la lectura, en leer para comprender, en la lectura como objeto artístico para desarrollar la educación estética, en las experiencias de lectura literaria compartida estimulantes y motivadoras que desarrollan la competencia literaria y amplían el horizonte de expectativas de cada lector.

\section{3- Los cuentos de hadas favorecen el desarrollo del pensamiento crítico, la educación en}

\section{igualdad y la no discriminación.}

- Los cuentos proporcionan diferentes mensajes que contienen y desarrollan el pensamiento simbólico.

- Son metafóricos.

- Las historias enseñan a los niños que cualquier situación por muy difícil que resulte tiene una solución.

- Es interesante destacar la identificación con el héroe o la heroína que supera las dificultades con el OGRO (o el personaje más malvado) con el que puede luchar.

- Los cuentos ayudan a proyectar sus enseñanzas a la vida real.

- Los cuentos de hadas constituyen un tipo de relato favorable y apropiado a esta etapa de desarrollo del niño (6 años). Es motivadora y comprometida.

- Actualmente solo son conocidas las versiones de Disney y sus clásicos; ofrecen una imagen de las mujeres bastante débil. Aunque a mí, a pesar de todo, me gustan las nuevas películas de la factoría Disney como Frozen, donde las mujeres saben resolver los conflictos por ellas mismas.

- $\quad$ Actualmente los cuentos tradicionales son menos leidos porque son considerados sexistas. A veces el docente puede proponer nuevas versiones cambiando los aspectos negativos y manteniendo lo positivo.

Los docentes valoran positivamente la lectura de los cuentos de hadas incluso cuando puedan ser entendidos como transmisores de estereotipos sociales, en ese caso pueden servir para mostrar esos estereotipos y deconstruirlos. En los componentes del discurso de los docentes emerge la dialéctica sexismo/igualdad y la no discriminación o el juego identificación/identidad en la infancia, cuestión fundamental, o la formación del pensamiento simbólico y crítico, la ideología, la moral, la superación de los conflictos de la maduración y la evolución psicológica infantil.

\section{Propuestas docentes para la enseñanza de los cuentos de hadas}

Se solicita a los docentes mediante cuestionario de respuestas abiertas y/o entrevistas que respondan a las siguientes preguntas. Muchas de ellas coinciden, se transcriben agrupadas temáticamente y por categorías. La participación de los docentes es muy positiva y nos permite conocer, desde las prácticas efectivas de la literatura en la escuela, la realidad de su preocupación por mejorar la experiencia de la 
Elvira Luengo Gascón

lectura y la recepción de los lectores.

Christiane Connan-Pintado ${ }^{7}$ en una experiencia realizada en 2008 en el contexto de la educación literaria en Francia, concluye después de llevar a cabo su investigación en niveles educativos similares que

La lecture des contes détournés invite à se poser des questions sur la définition de la littérature, ses finalités, ses procédés et les valeurs qu'elle véhicule. C'est sans doute à la formation de se donner les moyens de travailler dans ce sens sur des oeuvres éminemment passionnantes tant sur le plan littéraire que culturel puisqu'elles offrent le double avantage de faire revisiter le patrimoine tout en initiant à une riche palette de techniques littéraires. (Connan-Pintado, 2008, p. 124).

\section{1 ¿Qué cambios propondría para una buena educación literaria?}

- Comentario de los libros tanto en casa como en las escuelas

- Comentario sobre libros en el hogar y en las escuelas

- Leer el maestro en voz alta las obras literarias completas

- Compartir sus libros y recomendar sus favoritos a sus colegas.

- Fomentar las reuniones literarias

- Darle importancia al plan de lectura.

- Intercambiar libros de la biblioteca, es una práctica muy gratificante

- Compartir los libros y recomendar sus favoritos a los colegas.

Las maestras y maestros exponen su visión de las cuestiones fundamentales que afectan directamente a la lectura y a sus prácticas didácticas con las que conviven cotidianamente. Incluso comentan alguna cuestión sorprendente, como sorprendentes son las reflexiones de los niños y niñas que son capaces de emitir juicios como este que anotamos a continuación:

- Ante la pregunta: ¿Cuáles son las princesas del siglo XXI? Las reacciones de los niños son sorprendentes: ingenieros, modelos, deportistas, etc. y mi madre que trabaja duro.

\section{2 ¿Cómo leer?}

Ante esta pregunta, sumamente concreta, se despliega un abanico de respuestas que detectan la realidad, las carencias y las cuestiones básicas del estado de la cuestión y de la problemática; quizá, de la necesidad de mayor formación en cuanto a una variedad de recursos y de estrategias didácticas para los mediadores. Las respuestas se han agrupado por categorías o centros de interés.

\section{Modos, gustos, sugerencias de lectura...}

- Trabajar menos determinados aspectos, como por ejemplo la gramática (conceptos abstractos) y dedicar más tiempo a la lectura-comprensión.

-Más lectura comprensiva

- Deberíamos tener más tiempo de lectura, teatro, lecturas compresivas y menos temas de gramática.

- Fomentar el gusto por la lectura intentando que los alumnos lean más que hacer trabajos sobre los libros. Realizar

7 Veáse también: Christiane Connan-Pintado (2009). Lire des contes détournés à l'école. À partir des Contes de Perrault. De la GS au CM2. Paris: Hatier. Y Catherine Tauveron (2002). Lire la littérature à l'école. Pourquoi et comment conduire cet apprentissage spécifique? De la GS au CM. Paris: Hatier 
El cuento de los Hermanos Grimm «El Rey rana o Enrique-el-férreo»: recepción del lectorado...

versiones propias, utilizar diversidad de formatos.

- "Conocer" estrategias diversas de lectura que incluyan también poesía, comic, biografías, inventadas...etc. y no solo narrativa.

- Creo que en mi centro la apuesta que se hace por la educación literaria es positiva, un ejemplo de ello son las tertulias literarias

- Recomendar a los niños la lectura de clásicos adaptados o fragmentos de los clásicos originales

- Más talleres de lecturas teatralizadas, más tiempo, más cuenta cuentos.

- En los libros de texto de $1^{\circ}$ no hay ni una sola lectura escrita

- Lectura libre pero motivada

- Que se fomentara la lectura de cuentos a los niños, a las niñas (incluidos los de $6^{\circ}$ ) les gusta que les lean.

\section{La lectura en familia}

- Leer en familia y comentar los libros leídos.

- Motivar a los niños a leer desde infantil y también desde casa.

- Poner en casa un horario para leer juntos.

- Interés por parte de los padres. Comprar un libro les resulta como... cuando se gastan más en otras cosas.

- Primero que en la familia se practique y se dedique un tiempo para ello y luego en los colegios dedicar también un tiempo en la programación para ello.

- Trasladar el interés por la lectura a las familias, para que entre ellas y el colegio hubiera una buena coordinación

y llegaran a interesar a los alumnos

\section{La biblioteca}

- Visitar bibliotecas y librerías.

- Tener una biblioteca de aula variada

- Seguir con actividades de animación a la lectura. Rincón de lectura.

\section{La lectura como placer}

- Leer por placer, no como obligación. Los youtubers ayudan a "enganchar" al mundo literario.

-Libertad de elección de libros

- Fomentar el gusto por la lectura a través de actividades lúdicas, creativas y motivadoras para los niños

- Fomento de la lectura, no como una imposición si no como el instrumento que nos permite divertirnos y aprender de una manera diferente.

\section{3 ¿Qué cambios propondría para una buena educación literaria?}

- Talleres de lectura

- Para una buena educación literaria, se tienen que conocer los diferentes tipos de textos y tener una rutina y constancia en su uso.

- En nuestro centro, hemos analizado los estereotipos que se encuentran en los cuentos clásicos, de forma que, además de fomentar la animación lectora, hemos trabajado su análisis y reinterpretación, al tener que crear su propio cuento sin estereotipos, y posterior dramatización.

- Propondría diferentes tipos de textos, así como de géneros literarios. Además buscaría intercalar la literatura más tradicional con una más acorde a nuestros tiempos.

- Es fundamental una adecuada selección de textos, acorde a intereses, edad... de los niños. Se deben introducir todos los géneros literarios, no únicamente cuentos.

- Seleccionar los cuentos clásicos desde infantil hasta primaria. Secuenciándolos a su nivel de comprensión.

- Los cuentos tradicionales, cuentos de algunos autores que realmente cuentan algo y hacen pensar como los cuentos de Gianni Rodari o los de Roald Dahl o Arnold Lobel... y también adaptaciones para niños de obras clásicas (El Quijote y otros) y de poesía.

-Más actividades de animación en las que los niños no solo lean sino que hagan más dramatizaciones o actividades lúdicas en torno a los libros.

-Realizaría más actividades destinadas a la lectura, que fomenten la creatividad y la imaginación.

- Actividades lúdicas para iniciar la curiosidad e inquietudes en los alumnos.

- Eliminar las fichas resumen y tratar de desarrollar el amor por los libros ofreciendo variedad de temas para que cada 
uno escoja el más apropiado para él.

- Yo no obligaría a leer, sino que haría actividades en el centro que promovieran a ello.

- Dejar que los propios profesores utilicemos los libros o materiales necesarios que creamos para trabajar la literatura infantil sin que sean impuestos.

- Introducir dentro del horario cuentacuentos, dramatizaciones de cuentos, familias involucradas en dicha educación literaria y muchos más recursos literarios.

- Mayor dotación económica para proveer de un amplio abanico de libros donde los niños puedan elegir. Además mayores recursos personales y una educación más abierta sin estar tan limitadas por el uso de los libros de texto.

Los docentes coinciden en que el sujeto lector debe partir desde la experiencia personal de la lectura para garantizar esa transmisión como un enriquecimiento vital. Orientar a los estudiantes desde estos presupuestos debería ser, la prioridad del aprendizaje literario para cualquier docente.

\section{4 ¿Qué dificultades encuentra en su práctica docente?}

De nuevo, en este caso, anotamos las respuestas agrupadas por categorías que coinciden en los siguientes centros de interés; claramente se van repitiendo unas y otras en una de estas siete categorías emergentes que sintetizan las reflexiones de toda la muestra de participantes.

-No encuentro dificultades, es un factor de mi labor docente que "me encanta" y con la que alumnos y maestros nos contagiamos "la mayor es leer y compartir"

\section{Captar el interés de los alumnos}

- Que los niños se entretengan con la lectura. Les intento transmitir lo emocionante que es vivir historias, aventuras... conocer vocabulario...

- La dispersión a la hora de ponerse a trabajar.

- Que no todos los cuentos son de interés para los alumnos.

- Sobre todo la falta de interés de los alumnos, todo hay que trabajarlo muy lúdico.

- La falta de motivación. A los niños les parece algo aburrido, mecánico y sin sentido ni significatividad. No les hace disfrutar.

- La falta de autodisciplina en el alumnado y la dispersión

- A priori los niños no tienen una buena predisposición a la lectura pero una vez se adentran en la aventura literaria les encanta. Lo que no les suele gustar es hacer después más trabajo (resumen de la lectura, comentarios...)

\section{2. ¡El tiempo! y la cantidad de temario}

-Falta de tiempo para el momento de preparación de las variadas y diferentes inquietudes e implicaciones -Falta de tiempo, aunque dedicamos una sesión fija a la semana para trabajar la animación lectora.

- Las programaciones y el tiempo para llevar a cabo más actividades de ese tipo.

- La dificultad mayor es realizar actividades no planteadas en el programa ya que después no da tiempo a terminarlo.

-Falta de tiempo para este tipo de actividades por tener que ir "Corriendo" para cumplir un programa.

- La escasez de tiempo para trabajar la lectura de una forma más profunda con los alumnos.

- Que a veces hay tanto temario en los libros que da poco tiempo a practicar la animación a la lectura 
El cuento de los Hermanos Grimm «El Rey rana o Enrique-el-férreo»: recepción del lectorado...

\section{Dificultades a causa del vocabulario, la comprensión lectora...}

- En cuanto a literatura los niños encuentran dificultades en cuestión de vocabulario y comprensión lectora. - Los niños y niñas cada vez leen menos. En casa tampoco se les lee. Todo ello hace que a la hora de expresarse por escrito sean incapaces de hacerlo con imaginación.

\section{Dificultades fuera del entorno escolar}

- La principal dificultad la encuentro fuera del entorno escolar

- Leen poco en casa. En cada clase hay una pequeña biblioteca con lecturas adecuadas a la edad de los alumnos. Estos se pueden llevar los libros a casa ... pero no suele salir de la cartera en la mayoría de los casos.

-La educación literaria y lectora en las familias. A los niños de pequeños les gusta leer y que les lean. Hay que dejar que cuando avanzan en edad vayan eligiendo sus propias lecturas para que tengan su propio gusto literario. - Familias que sobreprotegen a los niños y, estos, cada vez llegan a Primaria más inmaduros, poco responsables, muy infantiles, con comportamientos poco autónomos.

- Al final, todos somos maestros y somos modelos. A los padres les pasa lo mismo, son modelos, y hay casas en las que no hay libros y eso es muy difícil cambiarlo.

- En cuanto a la literatura, está todo mediatizado. Los niños ven mucho la televisión y películas de modo que creen que todo lo saben porque todo les suena. En ese aspecto tendríamos que tener más cuidado con lo que ven en la tele; no todo es apropiado para ellos.

\section{La metodología utilizada}

- Los docentes deberán fomentar la lectura con libros que atraigan y enganchen a sus alumnos según la edad. Hacerlos críticos es necesario para que crezcan como personas.

- Pienso que la mayoría de los cuentos atraen a los niños ya que son caros y curiosos. Pero tendrían menos dificultades si a la hora de contarlos fuese más atractiva esa forma de contarlo.

- No tener al alcance versiones originales.

- Secuenciar la variedad de textos para trabajarlos con distintos niveles a la vez.

\section{Las programaciones didácticas}

- El volumen de contenidos en el área de Lengua y literatura dificulta una enseñanza dedicada a la literatura.

- Demasiadas cosas que trabajar, innovaciones que introducir, programa que cumplir, etc.

- Tener que llevar absolutamente los mismos temas y recursos en los tres cursos de nivel, el repetir las UDIS cada año etc. Esto no facilita el poder trabajar lo que crees más interesante.

- Libros de texto.

- Coordinación en el nivel.

- Las programaciones y la falta de tiempo para la realización de actividades que incluyen propuestas para la animación a la lectura y el gusto por los textos literarios.

- La dificultad mayor es realizar actividades no planteadas en el programa ya que después no da tiempo a terminarlo.

\section{El sistema educativo}

- Falta de recursos por parte de la administración.

- Pregunta muy dificil de responder de forma abreviada. Las dificultades a nivel general son de diferentes tipos: elevada ratio (25 alumnos en $1^{\circ}$ y $2^{\circ}$ ) y pocos apoyos en las aulas (falta plantilla en los centros para poder asignar apoyos y realizar desdobles).

- El volumen de contenidos en el área de Lengua y literatura dificulta una enseñanza dedicada a la literatura.

- Existe un sistema educativo encorsetado con libro de texto que dificulta la mayor presencia de la literatura en 
las aulas.

Para finalizar con los cuestionarios a las maestras y maestros de Educación primaria se han mostrado las respuestas a la pregunta ¿Qué dificultades encuentra en su práctica docente? Hemos agrupado las respuestas en siete categorías y todas ellas se nutren de respuestas certeras y coincidentes que emanan de la experiencia en centros educativos de procedencias muy variadas (rurales, urbanos, concertados y públicos) en la comunidad de Aragón. Llama la atención que la categoría que menos se menciona y que menos dificultades ocasiona en la práctica docente es la que tiene que ver con la falta de comprensión lectora y los problemas de vocabulario en los niños y niñas. Hay muchas más respuestas que se repiten en todas las categorías de forma bastante equilibrada entre las seis restantes.

La totalidad de las respuestas las hemos categorizado bajo los siguientes epígrafes:

Captar el interés de los alumnos. ¡El tiempo! y la cantidad de temario. Dificultades en cuestión de vocabulario y comprensión lectora. La principal dificultad la encuentro fuera del entorno escolar. La metodología utilizada. Las programaciones didácticas. El sistema educativo.

En el total de respuestas aparecen tres que indican que no tienen ninguna dificultad, una de ellas, muy entusiasta, señala:

"No encuentro dificultades, es un factor de mi labor docente que "me encanta" y con la que alumnos $y$ maestros nos contagiamos "la mayor es leer y compartir".

Esta pregunta correlaciona muy positivamente con las anteriores en las que se preguntaba acerca de la manera en que se lee, la conceptualización de la lectura y la educación literaria. Las propuestas son muy interesantes y enriquecedoras y la colaboración ha sido muy valiosa para conocer la realidad social y educativa de la recepción de nuestro cuento, los estereotipos culturales de género y las prácticas didácticas en los colegios, entre otros muchos matices, que se desprenden de las voces autorizadas de los responsables de formar a niños y niñas en la educación literaria. Amablemente han colaborado en esta investigación para volcar, anónimamente, en estas páginas sus inquietudes y su quehacer docente, lo que agradecemos sinceramente.

Un último testimonio: "Desde el centro estamos muy agradecidos de poder formar parte de este proyecto y siempre animamos a la realización de más experiencias de este tipo que suponen un 
El cuento de los Hermanos Grimm «El Rey rana o Enrique-el-férreo»: recepción del lectorado...

enriquecimiento para ambas partes, los estudiantes y nuestros alumnos ",8

\section{Conclusiones}

Se ha demostrado la existencia de algunos roles de género muy marcados en nuestra sociedad y los cuentos populares, en ocasiones, en este caso con el ejemplo de "El Rey rana", contribuyen e influyen en la formación de estereotipos de género, no obstante, en nuestro cuento se aprecia un acto de desobediencia por parte de la princesa al rebelarse contra el mandato del rey lanzando a la rana contra la pared. Sin embargo, para deconstruir esos modelos femeninos estereotipados y patriarcales, mediante la práctica docente, podemos invertir ese proceso construyendo otros modelos. Desarrollando la imaginación en las niñas y niños y fomentando el pensamiento crítico se puede recrear y reescribir esos cuentos actualizando su lectura desde la experiencia personal de su propio mundo. Solo una activación de la literatura como modo de acceso propio al mundo. Como señala Schaeffer:

seule une activation de la littérature comme mode d'accès propre au monde, c'est à-dire seule l'entrée de l'enfant ou du jeune dans l'expérience personnelle que constitue la lecture des œuvres, peut garantir que cette transmission soit autre chose qu'un savoir mort. Guider les élèves vers cette expérience devrait donc, en toute logique, constituer le cœur même de l'apprentissage littéraire (citado en Vibert 2012, p. 117).

Anne Marie Chartier (2002, p. 157) recuerda la responsabilidad y el poder que los maestros tienen a la hora de perpetuar el imaginario colectivo pues se halla en sus manos la elección de los libros que los niños leen de la mano de las directrices institucionales:

Nada está ya decidido, porque el poder práctico reside, en última instancia, en manos de los maestros. Son ellos quienes, a través de la experiencia con los niños, eligen y continuarán eligiendo los « libros para las clases » que sería conveniente llamar por su nombre: « los clásicos » (citado en Colomer, 2010, p. 101)

"El Rey rana" en la recepción de los diferentes niveles de lectura funciona como un texto "reticente" y "proliferante", tomamos estos términos de Catherine Tauveron.

¿La figura del enseñante de la Universidad podría representar el cambio hacia una nueva educación literaria? El profesor de las facultades de educación es un formador de formadores. Los nuevos docentes deberían formar buenos lectores. Es necesario que conozcan las estrategias de enseñanza-

8 Agradecemos a los estudiantes del grupo 1 de segundo curso de Magisterio de Educación Primaria en el curso 20152016 de la Facultad de Educación que han colaborado en la recogida de los cuestionarios a los docentes en los casi 50 colegios de la comunidad de Aragón. La experiencia ha sido llevada a cabo en otras tantas aulas de infantil y Primaria a la vez que han podido poner en práctica la experiencia didáctica de trabajar el cuento de "El Rey rana" y la conversación literaria con los niños y niñas de infantil y primaria junto a las maestras de los colegios, tras haberla preparado y puesto en práctica con todos ellos previamente en las aulas de la Universidad. La totalidad de las respuestas de las aplicaciones didácticas y de las conversaciones literarias de todos los niños y niñas alcanzan una muestra demasiado amplia para trasladar todos los resultados al espacio limitado de este artículo. 
aprendizaje más actuales y las más apropiadas para conseguirlo. Y es nuestra responsabilidad porque ¿"El Rey rana" es un cuento fantasma? Este cuento es un cuento universal y, como se ha demostrado, es un cuento olvidado pero reconocido por todos, pues permanece en el imaginario colectivo.

A lo largo de la investigación hemos constatado en las respuestas de los niños, las niñas, los estudiantes de la Universidad y los docentes que el mismo texto genera experiencias lectoras diversas y emociones variadas, las interpretaciones, los enigmas y las expectativas que suscita varían dependiendo de cada acto de lectura. De modo que se puede concluir y afirmar que se trata de un texto reticente y proliferante. Como señala Catherine Tauveron en La lecture comme jeu 1, à l'école aussi ${ }^{9}$

Est « réticent « tout ce qui concourt délibérément à créer des énigmes : silences, gommage des relations de cause à effet, brouillage ou contradictions des voix, brouillage des frontières des mondes, de la vérité et du mensonge, camouflage de la nature du narrateur, clins d'œil culturels au travers d'allusions à d'autres oeuvres...

Un texte « proliférant « appelle l'interprétation. Certaines réticences (comme le blanc) peuvent bien entendu être « proliférantes « à l'occasion.

Por otro lado, Tzvetan Todorov (2007) acusa en La littérature en péril que:

«Une conception étriquée de la littérature, qui la coupe du monde dans lequel on vit, s'est imposée dans l'enseignement, dans la critique et même chez nombre d'écrivains. Le lecteur, lui, cherche dans les œuvres de quoi donner sens à son existence. Et c'est lui qui a raison ». (cit. en Vibert, 2012) ${ }^{10}$.

La experiencia de los docentes descubre las diferentes estrategias didácticas para acercar la literatura a los niños, las buenas prácticas de educación literaria y lo que no funciona. Insisten en la importancia de elegir los libros con los niños y de no imponerles pesados programas que no les interesan. Captar el interés de los alumnos es primordial, desde la escuela y desde el entorno familiar, mediante actividades lúdicas que les motiven a leer. La metodología utilizada y las programaciones didácticas enmarcadas en un sistema educativo más abierto son cuestiones que reclaman mayoritariamente.

Los principales fundamentos teóricos sobre los cuales se apoyan las propuestas didácticas en la actualidad provienen del concepto de sujeto lector. Como plantea Anne Vibert (2012) el lugar preponderante que ocupa el lector tiene unas consecuencias para la enseñanza de la literatura. ¿Qué dispositivos didácticos se deberán utilizar con los estudiantes? ¿Cuáles son las dificultades con las que

9 Catherine Tauveron. La lecture comme jeu 1, à l'école aussi. En http://eduscol.education.fr/cid46330/sommaire.html 10 Vibert, A. (2012). Élèves acteurs de la lecture analytique. Académie de Strasbourg.

http://www.ac-nice.fr/lettres/index.php/ressources-en-lettres/litterature/lire/147-mme-a-vibert-igen-faire-place-au-sujetlecteur-en-classe. 
El cuento de los Hermanos Grimm «EI Rey rana o Enrique-el-férreo»: recepción del lectorado...

se encuentran? A estas preguntas han respondido los docentes de nuestra investigación revelando un panorama real que representa no al lector modelo del que habla Umberto Eco sino al lector empírico, real. De esta manera desde sus experiencias concretas nos han expresado sus propuestas para una educación literaria de calidad y hasta qué punto son conciliables con los objetivos de los programas y con la selección del corpus de lecturas que se les proponen a los lectores de cada uno de los centros educativos en los que hemos intervenido.

Los docentes han mostrado ser conocedores de las nuevas bases teóricas y del (re)descubrimiento del lector con las llamadas teorías de la "Recepción" impuestas a finales de los años setenta y principios de los ochenta centradas en el lector (y no en el texto) el cual se reubica en el centro de la actividad crítica. Hasta entonces, las teorías dominantes se caracterizaron por la prioridad otorgada al texto. La ruptura teórica se ha traducido asimismo por el cambio de interés de los investigadores del texto al lector, una verdadera revolución conceptual, que supone la fuente de una renovación de los estudios literarios (Rouxel, Langlade, 2004, cit. en Vibert, 2012) ${ }^{11}$. Anne Vibert (2012) planteaba ya esta concepción de « sujet lecteur en classe : quelles voies pour renouveler les approches de la lecture analytique au collège et au lycée?»

De hecho, varias investigaciones afirman que la fuente del significado no está realmente o no solo está en el texto, sino también, y quizá primero en el receptor, es el lector quien actualiza el texto. Para finalizar, dos ideas deben ser recordadas en este protagonismo del papel del lector, como analiza Anne Vibert (2012), la primera: "siempre que no se materialice en una lectura determinada, el texto es un producto inacabado, un mensaje puramente virtual" y la segunda: “considerado en sí mismo, el texto es un conjunto de indeterminaciones, aperturas de sentido que solo la colaboración activa de un lector puede transformar en un sistema organizado de signos".

Teniendo en cuenta que cada sujeto lector actualiza el texto, construyendo y deconstruyendo estereotipos, el enigmático cuento de "El Príncipe rana" se ha convertido en un texto muy prolífico, proliferante, expuesto a una polifonía de sentidos en la recepción de las múltiples lecturas infantiles, docentes, reescrituras, críticas y miradas de artistas de signo crossover.

11 Puede verse en « La question du sujet lecteur en didactique de la lecture littéraire », dans Falardeau Eric et al. (dir.), Les voies actuelles de la recherche en didactique du français. Québec, Presses de l’Université de Laval, 2007, p. 110. 


\section{Bibliografía:}

Beckett, S. L. (2013). Crossover Picturebooks: A Genre for All Ages. Routledge.

Bettelheim, B. (2012). Psicoanálisis de los cuentos de hadas. Barcelona: Crítica.

Camarena, J. y Chevalier, M. (1995). Catálogo tipológico del cuento folklórico español. Cuentos maravillosos, vol. 1. Madrid: Gredos.

Conan-Pintado, C. et Tauveron, C. (2013). Fortune des Contes des Grimm en France. ClermontFerrand: Presses Universitaires Blaise Pascal.

Connan-Pintado, C. (2008). Heurs et malheurs dans la réception des nouveaux programmes sur l'enseignement de la littérature à l'école. Analyse de pratiques: la lecture des contes détournés en Pratiques effectives de la littérature à l'école et au collège. Coord. Danielle Dubois-Marcoin et Catherine Tauveron. Repères. Recherches en didactique du français langue maternelle. 37. Pp. 105-129.

(2009). Lire des contes détournés à l'école. À partir des Contes de Perrault. De la GS au CM 2. Paris: Hatier.

Colomer, T. (2010). Introducción a la literatura infantil y juvenil actual. Madrid: Síntesis. $2^{\mathrm{a}}$ ed.

Delpech, F. (1994). De l'héroïsme féminin dans quelques légendes de l'Espagne du siècle d'or. Ébauche pour une mythologie matronale en Augustin Redondo (ed.), Images de la femme en Espagne aux XVIe et XVIIe siècles. Presses de la Sorbonne Nouvelle, pp. 13-31.

Dubois, R. (1977). Littérature enfantine et progrès social.

Eco, U. (1979). Lector in fabula. Barcelona: Lumen.

Espinosa, A. M. (1987, 1988). Cuentos populares de Castilla y León, 2 vols. Madrid: CSIC.

Espinosa, A.M. (2009). Cuentos populares españoles, 3 volúmenes. (1945, 1947, 1947) . Madrid: Consejo Superior de Investigaciones Científicas.

Gervais, B. (1 993). À l'écoute de la lecture. Montréal : VLB éditeur.

Grimm, J. y W. (1987). I Cuentos de niños y del hogar. Introducción: Herman Grimm. Traducción: María Antonia Seijo Castroviejo. 2 Vol. Madrid: Anaya.

Janer, M.de la P. (2015). Los cuentos del animal-novio: los paradigmas de "Eros y Psique" y "La Bella y La Bestia” Ocnos. 14 pp. 114-123.

Lancner, H. (1984). Les Fées au Moyen Âge. Paris: Champiom. 
El cuento de los Hermanos Grimm «EI Rey rana o Enrique-el-férreo»: recepción del lectorado...

Lecouteux, C. (1982). Mélusine et le Chevalier au Cygne. Paris: Payot.

Louichon, B. (2009). La littérature après coup. Rennes: PUR, coll. « Paideia ».

Luengo Gascón, E. (2007). Diacronía y Semiótica del cuento folclórico. El poder de El conde Partinuplés: Un juego entre la palabra y el sentido. Lectura y universidad. (Seminario interfacultativo de lectura) coord. por Eloy Martos Núñez, Ángel Suárez Muñoz, Agustín Vivas Moreno, pp. 311-316.

(2014). La reinvención de la identidad femenina bajo el monomito universal. en Contenidos especializados en la enseñanza superior. Coord. Graciela Padilla Castillo. Editorial ACCI. Colección Nuevo Impulso Educativo. España. pp. 305318.

Mendoza Fillola, A. (1999). Función de la literatura infantil y juvenil en la formación de la competencia literaria en Pedro Cerrillo y Jaime García Padrino (coords.), Literatura infantil y su didáctica, Cuenca, Universidad de Castilla-La Mancha, pp. 11-53. También en http:// www.cervantesvirtual.com/obra/funcin-de-la-literatura-infantil-y-juvenil-en-la-formacin-dela-competencia-literaria-0/. Última consulta: 12-9- 2017.

Montardre, H. (1994). Le personnage féminin dans la littérature de jeunesse en Jean Perrot et Véronique Hadengue. Écriture féminine \& littérature de jeunesse pp. 25-31. Paris : Institut International Charles Perrault. La Nacelle.

Picard, M. (1986). La Lecture comme jeu. Collection Critique. Éditions de minuit.

Rodríguez Almodóvar, A. (1990). Cuentos al amor de la lumbre, 2 volúmenes. Madrid: Grupo Anaya Stubss, M. (1983/87): Discourse Analysis. The sociolinguistic Analysis of natural Language. Blackwell. Oxford. (Análisis del Discurso. Madrid. 1987).

Tatar, M. (2012). Los cuentos de hadas clásicos anotados. Prólogo y edición. Barcelona: Crítica.

Tauveron, C. La lecture comme jeu 1, à l'école aussi. En http://eduscol.education.fr/cid46330/ sommaire.html. Última consulta: 5-9-2017.

(1999). Comprendre et interpréter le littéraire à l'école : du texte réticent au texte proliférant. In: Repères, recherches en didactique du français langue maternelle. Comprendre et interpréter les textes à l'école, n¹9 pp. 9-38. http://www.persee.fr/doc/reper_1157-1330_1999_ num_19_1_2289. Última consulta: 10-9-2017. 
(2002). Lire la littérature à l'école. Pourquoi et comment conduire cet apprentissage spécifique? de la GS au CM. Paris : Hatier.

Thomas, J. J. (1978): «Théorie générative et poétique littéraire», en Langages, 51, pp. 7-64.

Thompson, S. (1972). El cuento folclórico. Caracas: Universidad Central de Venezuela.

Tzvetan, T. (2007). La littérature en péril, Paris: Flammarion.

Vibert, A. (2012). Élèves acteurs de la lecture analytique. Académie de Strasbourg.

http://www.ac-nice.fr/lettres/index.php/ressources-en-lettres/litterature/lire/147-mme-a-vibert-igenfaire-place-au-sujet-lecteur-en-classe. Última consulta: 22- 11-2017. 